\title{
A comparative analysis of flood damage models: lessons learnt and future challenges
}

\author{
Chiara Arrighi ${ }^{1}$, Francesco Ballio ${ }^{2}$, Francesca Carisi ${ }^{3}$, Fabio Castelli ${ }^{1}$, Alessio Domeneghetti ${ }^{3}$, Alice Gallazzi ${ }^{2}$, Marta \\ Galliani ${ }^{2}$, Frédéric Grelot ${ }^{4}$, Patric Kellermann ${ }^{5}$, Heidi Kreibich ${ }^{5}$, Daniela Molinari ${ }^{2}$, Guilherme S. Mohor ${ }^{6}$, Markus \\ Mosimann ${ }^{7}$, Stephanie Natho ${ }^{6}$, Claire Richert ${ }^{4}$, Kai Schroeter ${ }^{5}$, Anna Rita Scorzini ${ }^{8}$, Annegret H. Thieken ${ }^{6} \&$ Andreas P. \\ Zischg $^{7 *}$ \\ ${ }^{1}$ University of Florence, Dept. of Civil and Environmental Engineering DICeA, Firenze, Italy \\ ${ }^{2}$ Politecnico di Milano, Dept. of Civil and Environmental Engineering DICA, Milano, Italy \\ ${ }^{3}$ University of Bologna, Dept. of Civil, Chemical, Environmental and Material Engineering DICAM, Bologna, Italy \\ ${ }^{4}$ G-EAU, Univ Montpellier, AgroParisTech, CIRAD, IRD, INRAE, Montpellier SupAgro, Montpellier, France \\ ${ }^{5}$ GFZ German Research Centre for Geosciences, Section Hydrology, Potsdam, Germany \\ ${ }^{6}$ University of Potsdam, Institute of Environmental Science and Geography, Potsdam, Germany \\ ${ }^{7}$ Institute of Geography, Mobiliar Lab for Natural Risks, Oeschger Centre for Climate Change Research, University of Bern, Bern, \\ Switzerland \\ ${ }^{8}$ University of L'Aquila, Dept. of Civil, Environmental and Architectural Engineering, DICEAA, L'Aquila, Italy \\ ${ }^{*}$ Authors are listed in alphabetical order
}

\begin{abstract}
Flood damage assessment is crucial to address the challenges of climate and socio-economic changes. Researchers and practitioners have developed several damage models to tackle local and regional situations. Particularly for direct damages to the residential sector, these models rely on numerous hypothesis (e.g. zero damage threshold) and parameters (e.g. recovery costs) assumed to fit specific local conditions and available data. Thus, transferability of damage models and reliability of observed losses have become key topics in the debate.This work aims at understanding the behaviour of different residential building damage models through their application to a case study in order to compare assumptions, estimated exposure values and losses. The research work is designed as a "blind" exercise where different research groups make a damage assessment starting from the same building dataset. Nine models are applied to estimate exposure and damage at the single-building scale. The results are compared in terms of exposure values, total damage and individual building damage. Although damage models differ in assumptions and parameters, the application highlights a good correlation among models in terms of exposure and relative damage, while correlation with monetary damage recorded in claims is low.
\end{abstract}

\section{Introduction}

The estimation of flood losses implies the use of vulnerability/exposure models for flood damage and risk assessment (Meyer et al. 2013; Zischg et al. 2018; Wagenaar et al. 2018; Molinari et al. 2019). According to Gerl et al. (2016), in central Europe there are 28 models with 652 functions to assess flood losses, whereas almost half of the functions refer to residential buildings. The main differences among damage models are: (i) spatial scale, (ii) metric (i.e. absolute or relative loss), (iii) exposure assessment (i.e. whole building or affected floors, market values or reconstruction-replacement costs), (iv) number of input variables, (v) calibration/validation

a Corresponding author: chiara.arrighi@unifi.it

DOI 10.3311/FLOODRisk2020.9.15 with observed losses. These differences pose the issue of model transferability to other urban or environmental contexts.

With a joint effort of eight research groups, the objective of this study is to test and compare damage models for residential buildings used or developed by each group, by applying them in a "blind exercise", i.e. a common flood case study characterised by high availability of hazard and building data, with unknown information on observed losses in the implementation stage of the models.

As the research groups use approaches representing many different types and characteristics of models (e.g. univariable - multivariable; absolute - relative; graduated - regression - machine learning), being calibrated based 
on empirical data stemming from different countries (Austria, France, Germany, Italy, Japan, Netherlands), with different landscapes, the blind exercise provides an extensive comparison of models and their transferability. The analysis of the differences in the ensemble of model outcomes aims at pointing out common patterns or divergent behaviours between model outcomes and with respect to observed losses.

\section{Method}

Nine damage models for residential buildings were selected for the study. They are shortly described below; further model details can be found in the respective references and in Molinari et al. (2020):

- $\quad$ the model by Arrighi et al. (2018a, 2018b) is a synthetic model which associates a relative physical damage to flood depth and then calculates a monetary damage as a function of the recovery cost (as a fraction of market value). The relative damage is calculated through two piecewise linear stage-damage curves for buildings with and without basement. The model was created based on expert judgement for the city of Florence (Italy) and applied both at building and census block scale (Arrighi et al. 2018a, 2018b)

- The model developed by CEPRI (European Center for Flood Risk Prevention) is a synthetic multi-variable model expressing absolute damage as the expected sum of the actions required after a flood to go back to the pre-flood state. Water depth, submersion duration and building characteristics are considered (CEPRI, 2014a, b; Richert \& Grelot, 2018).

- The model by Dutta et al. (2003) is a simple model considering flood depth only. The model supplies a relative damage, i.e. the degree of loss that describes the ratio of loss to the replacement value of the whole building; basement, number of exposed floors or other exposure variables are not separate inputs for the model, but are part of its variance.

- FLEMOps (Flood Loss Estimation MOdel for the private household sector) is a multi-variable, rule-based model estimating relative monetary flood loss to residential buildings as a function of water depth, building type and building quality, whereby it is not further differentiated between flooded floors, and the (non-)existence of a basement is not considered (Thieken et al. 2008). The model is empirically derived from data collected from 1697 households affected by the severe flooding of the rivers Elbe, Danube and some of their tributaries in August 2002 in Germany.

- The model by Fuchs et al. (2019) is a simple model considering flow depth only. It is a function developed for mountain areas, i.e. referring to house building tradition of the Alps and flood processes with sediment transport. The model supplies a relative damage, i.e. the degree of loss that describes the ratio of loss to the replacement value of the whole building.

- INSYDE (Dottori et al., 2016, Molinari et al. 2017) is an expert-based synthetic model developed for the Italian context. INSYDE adopts 23 input variables, six describing the flood event and 17 referring to building features. The model supplies damage in absolute terms by considering the replacement/recovery value of damaged components, and by referring only to flooded floors (including basement, if present). It was validated for different Italian flood events (Dottori et al., 2016; Molinari et al. 2017; Amadio et al. 2019).

- The model by Jonkman et al. (2008) is a simple model considering flow depth as the only explicative variable, calibrated on loss data in the Netherlands. As for Dutta et al. (2003) and Fuchs et al. (2019), the model supplies damage in relative terms.

- Carisi_MV (Carisi et al. 2018) is an empirical multi-variable model based on random forest approach, which estimates relative building losses considering six explicative variables: maximum water depth, maximum flow velocity, flood duration, monetary building value per unit area (based on market value), structural typology and footprint area of each building (Carisi et al. 2018). Calibration data come from a real inundation event by the Secchia river, in the province of Modena (Italy) in 2014. The model does not consider damages to basements.

- Carisi_sqrtmono (Carisi et al. 2018) is an empirical uni-variable model, calibrated on the previously cited 2014 Secchia flood event. The model supplies the relative damage to the building (using the market value to relativize the observed monetary damage), as a function of the maximum water depth $\mathrm{h}(\mathrm{m})$. The model doesn't consider basements or garages, for coherence with the calibration context.

The above models have been applied starting from common data available in the study area (see sect. 3). The results have been compared first among models and then versus the observed losses.

\section{Case study}

The study area is the town of Lodi (Italy), which in November 2002 was hit by a flood, caused by the overflow of the Adda River, which caused severe losses to buildings and economic activities. The event was chosen as reference for the exercise because it is well documented and hazard, exposure and vulnerability data are available. A 2D hydraulic reconstruction of the event is also available 
(Scorzini et al. 2018), as well as micro-scale information on exposure and vulnerability of residential buildings.

Observed damage is known for 345 of the 877 flooded buildings, as derived from claims compiled by citizens after the occurrence of the flood, to ask for public compensation. Claim data have been stored in a georeferenced database by a team of researchers of Politecnico di Milano including information on the owner, the address of the flooded building, its typology (e.g. apartment, single house), the number of affected floors, a description of the physical damage and its translation in monetary terms (distinguishing, for the different rooms the building is made of, among damage to walls, windows and doors, floor, systems and content).

\section{Results and discussion}

In order to identify commonalities and dissimilarities among the different flood damage models, first, exposure estimates were compared, and, second, estimated losses have been compared to observed losses.

Table 1 shows the Pearson correlation coefficient for the estimated exposure. Although there are 9 models, exposure assessment can be common to different approaches, e.g. the models by Dutta et al. (2003), Fuchs et al. (2019), Jonkman et al. (2008). Table 1 shows very high correlation coefficients, meaning that all models start with a very similar approach for exposure assessment, although models have been developed for different contexts and different available data.

\begin{tabular}{|c|c|c|c|c|c|}
\hline & 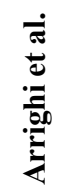 & 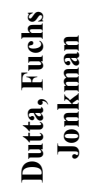 & $\sum_{\substack{|=1\\
|=1}}^{\infty}$ & 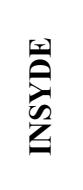 & 葛 \\
\hline Arrighi et al. & 1 & 0.87 & 0.96 & 0.97 & 0.98 \\
\hline $\begin{array}{l}\text { Dutta, Fuchs, } \\
\text { Jonkman }\end{array}$ & & 1 & 0.94 & 0.91 & 0.92 \\
\hline FLEMO-ps & & & 1 & 0.99 & 0.99 \\
\hline INSYDE & & & & 1 & 0.98 \\
\hline $\begin{array}{l}\text { Carisi } \\
\text { sqrtmono \& } \\
\text { MV) }\end{array}$ & & & & & 1 \\
\hline
\end{tabular}

Table 1. Pearson correlation coefficient for exposure estimates supplied by the models.

Less correlation is observed in monetary losses, since modelling approaches have several assumptions and differ in the shape of the damage functions and in the number of representative variables. For more details please refer to Molinari et al. (2020).

Table 2 shows a comparison between observed overall monetary losses and model estimates as well as the mean unitary monetary damage, i.e. the average ratio between loss $(€)$ and building footprint area $\left(\mathrm{m}^{2}\right)$. The damage models developed for Italian contexts (INSYDE; Arrighi et al. 2018 and Secchia by Carisi et al., 2018) and CEPRI model are those providing the best estimation of the overall amount of monetary damage, although these models yield quite different results in terms of unitary damage except for INSYDE and Secchia MV which give both $85 € / \mathrm{m}^{2}$.

\begin{tabular}{|l|c|c|}
\hline Model & $\begin{array}{c}\text { Total } \\
\text { Monetary } \\
\text { damage (M€) }\end{array}$ & $\begin{array}{c}\text { Mean unitary } \\
\text { monetary damage } \\
\left(\mathbf{€} / \mathbf{m}^{2)}\right.\end{array}$ \\
\hline Observed & 6 & 60 \\
\hline Arrighi et al. & 6 & 43 \\
\hline Carisi_MV & 8 & 85 \\
\hline Carisi_sqrtmono & 12 & 132 \\
\hline CEPRI & 10 & 74 \\
\hline Dutta et al. & 77 & 265 \\
\hline FLEMO-ps & 16 & 176 \\
\hline Fuchs et al. & 50 & 171 \\
\hline INSYDE & 9 & 85 \\
\hline Jonkman et al. & 14 & 49 \\
\hline
\end{tabular}

Table 2. Observed losses versus monetary estimates with models.

The average of the 9 damage models is $22 \mathrm{M} €$ that is about four times the observed loss. The model by Dutta et al., (2003) provides the higher estimate, more than twelve times the observed $6 \mathrm{M} €$. These differences can be easily observed also in the maps of Fig. 1-2, where the model outcomes and observed losses are represented. Given the number of maps, the results have been separated into two figures to ensure readability.

Figures 1-2 show with the same colour scale the estimated unitary losses (Fig. 1-2, panels b to j) and the observed losses (Fig. 1, panel a).

Also in the case of the model by Arrighi et al. (2018), which provides the closest estimate of the overall losses, the maps (Fig. 1, panels a, b) show several differences. In fact, although the estimates are close to observations we may notice that the model behaves 'smoothly' where water depths are quite homogenous (see the right hand side of the map, panel b) while observed losses (panel a) appear more variable in space, with very high and very low damages close one to another. This smoothing effect, although with different absolute values can be observed in all models, highlighting that single-building scale flood damage estimation is very challenging for modellers given the intrinsic variability and uncertainty of exposure and vulnerability at such small scale.

\section{Conclusions}

The blind test suggests that model transferability depends on the similarity between the area of implementation and the calibration context. In fact, models developed for the Italian studies performed generally better than others. Nevertheless, the maps show that models provide a smoother estimation with respect to actual claims, which is affected by high spatial variability and uncertainty at single-building scale. 

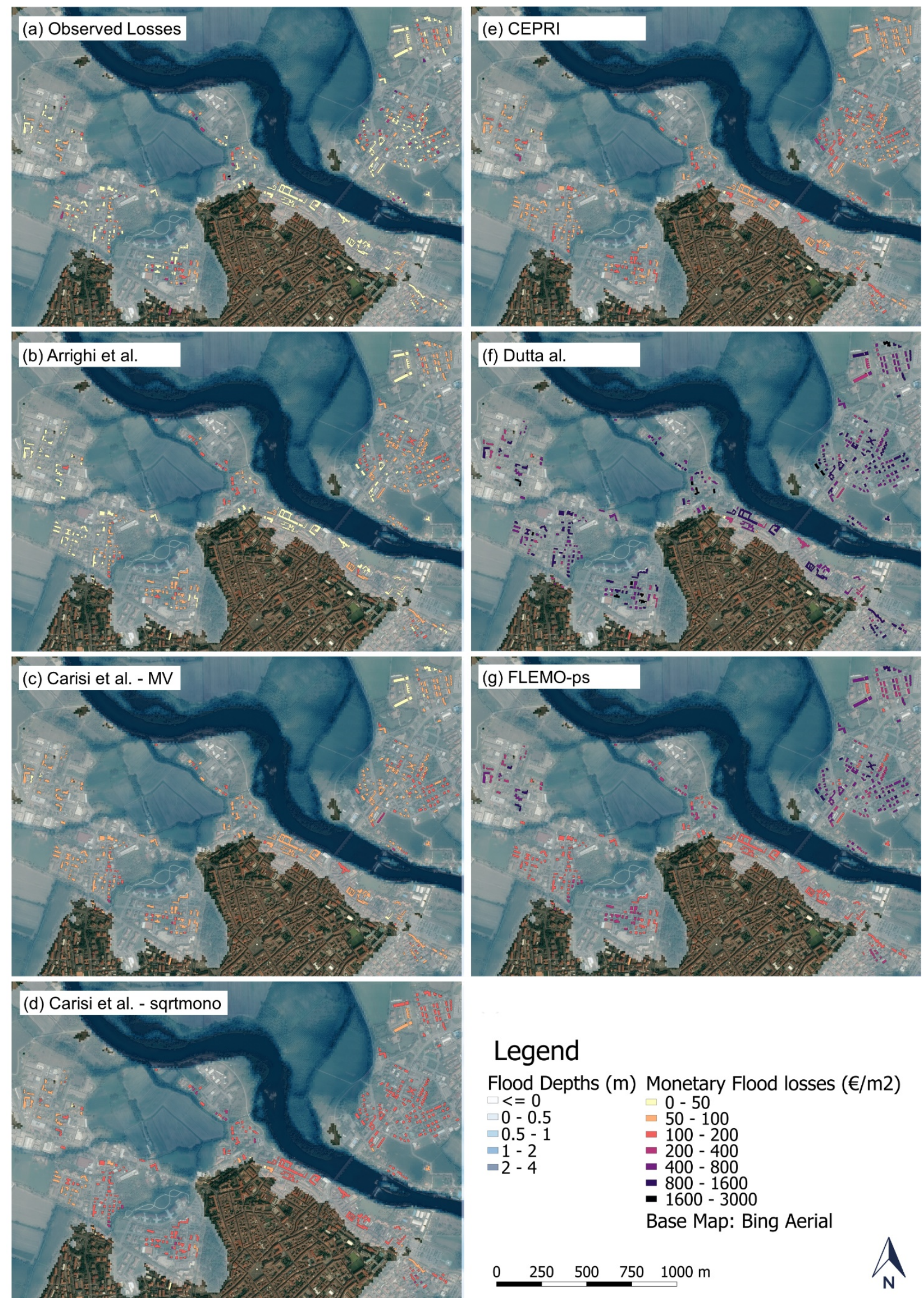

\section{Legend}

Flood Depths (m) Monetary Flood losses ( $€ / \mathrm{m} 2)$

$<=0$

$0-0.5$

$0.5-1$

$-1-2$

$=2-4$

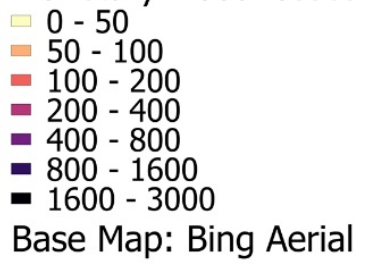

$\square-50$
$\square 50-100$

$100-200$

- $200-400$

- 800 - 1600

- 1600 - 3000

Base Map: Bing Aerial

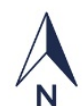

Figure 1. Comparative maps of unitary damage model estimates (b-g) and observed losses (a) (part 1)

${ }^{a}$ Corresponding author: chiara.arrighi@unifi.it DOI 10.3311/FLOODRisk2020.9.15 

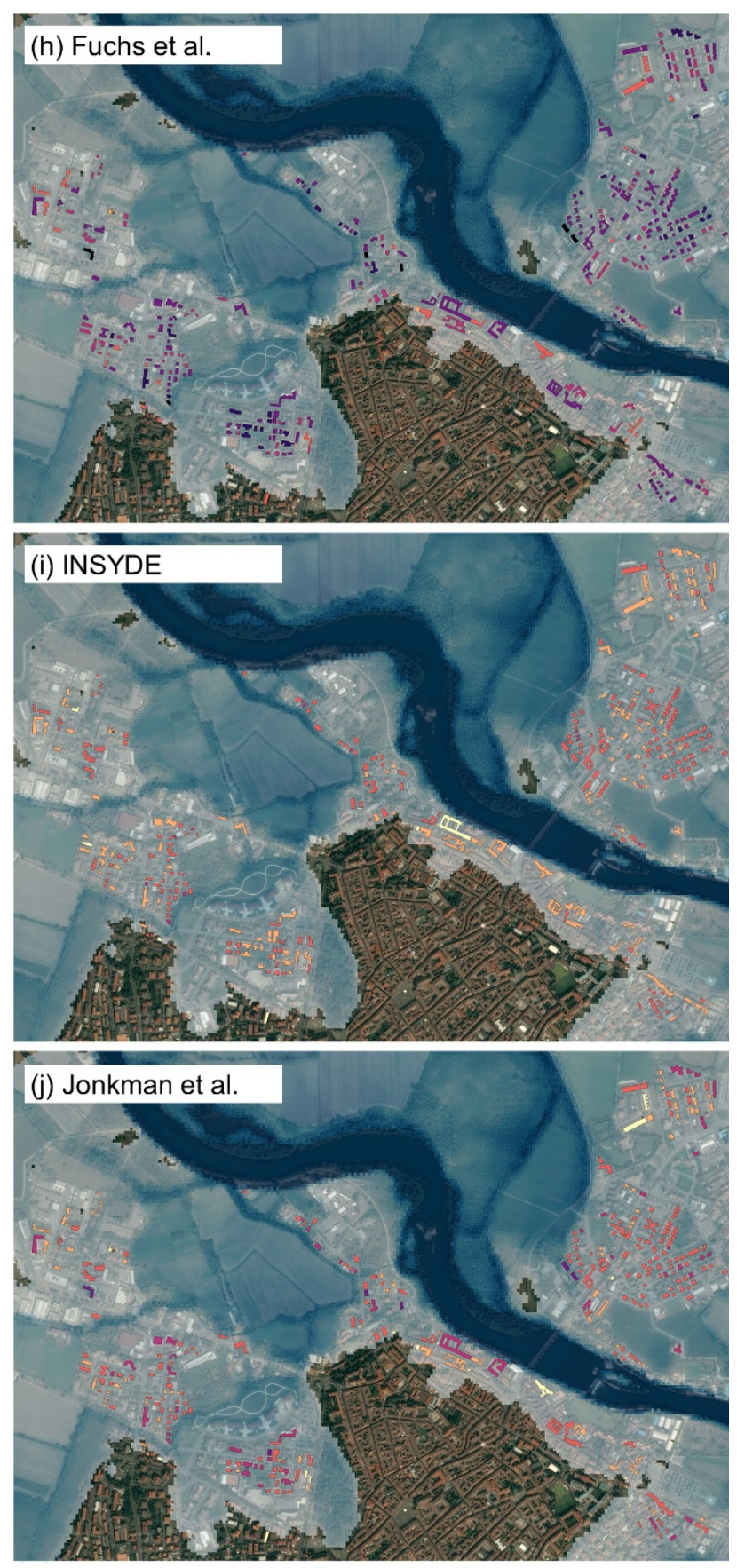

\section{Legend}

\begin{tabular}{|c|c|}
\hline $\begin{array}{l}\text { Flood Depths (m) } \\
<=0 \\
0-0.5 \\
0.5-1 \\
1-2 \\
=2-4\end{array}$ & $\begin{array}{l}\text { Monetary Flood losses }(€ / \mathrm{m} 2) \\
0-50 \\
50-100 \\
=100-200 \\
200-400 \\
=400-800 \\
=800-1600 \\
1600-3000 \\
\text { Base Map: Bing Aerial }\end{array}$ \\
\hline
\end{tabular}

$0 \quad 250 \quad 500 \quad 750 \quad 1000$
$m$

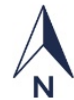

Figure 2. Comparative maps of unitary damage model estimates (h-j) (part 2)
This result suggests that a decrease in scale of application, e.g. census section (i.e. building block) or neighbourhood, could have positive effects in terms of capability of intercepting mean loss values.

Literature (e.g. Merz et al., 2013) generally suggests that including more variables in the models can improve accuracy, however in this blind test the simpler models (Carisi-sqrtmono or Jonkman et al., 2008) provide estimates comparable to multi-variable models (e.g. FLEMO-ps, CEPRI).

Further research could better investigate scale effects and observation uncertainties to improve the understanding of flood damage estimation.

\section{References}

1. Amadio, M., Scorzini, A.R., Carisi, F., Essenfelder, A.H., Domeneghetti, A., Mysiak, J. and Castellarin, A. (2019): Testing empirical and synthetic flood damage models: the case of Italy. In Nat. Hazards Earth Syst. Sci. 19 (3), pp. 661-678

2. Arrighi, C., Brugioni, M., Castelli, F., Franceschini, S. and Mazzanti, B. (2018a). Flood risk assessment in art cities: the exemplary case of Florence (Italy). Journal of Flood Risk Management 11, 616-631

3. Arrighi, C., Rossi, L., Trasforini, E., Rudari, R., Ferraris, L., Brugioni, M., Franceschini, S. and Castelli, F. (2018b) Quantification of flood risk mitigation benefits: A building-scale damage assessment through the RASOR platform. Journal of Environmental Management, 207, 92-104

4. Ballio F., Molinari D., Minucci G., Mazuran M., Arias Munoz C., Menoni S., Atun F., Ardagna D., Berni N. and Pandolfo C., (2018) The RISPOSTA procedure for the collection, storage and analysis of high quality, consistent and reliable damage data in the aftermath of floods, Journal of Flood Risk Management, 11, S604-S615

5. Cammerer, H., Thieken, A. H. and Lammel, J.: Adaptability and transferability of flood loss functions in residential areas, Nat. Hazards Earth Syst. Sci., 13(11), 3063-3081, doi:10.5194/nhess-13-30632013, 2013.

6. Carisi, F., Schröter, K., Domeneghetti, A., Kreibich, H. and Castellarin, A., 2018. "Development and assessment of uni- and multi-variable flood loss models for Emilia-Romagna (Italy)". Nat. Hazards Earth Syst. Sci., 18, 2057-2079.

7. CEPRI. (2014a). Evaluation des dommages liés aux inondations sur les logements.

8. CEPRI. (2014b). Evaluation des dommages aux logements liés aux submersions marines.

9. Dottori F., Figueiredo R., Martina M.L.V., Molinari D. and Scorzini A., INSYDE (2016): a synthetic, probabilistic flood damage model based on explicit cost analysis, Nat. Hazards Earth Syst. Sci., 16, 25772591

10. Dutta, D., Herath, S. and Musiake, K. (2003): A mathematical model for flood loss estimation. In Journal of Hydrology 277 (1-2), pp. 24-49

\footnotetext{
a Corresponding author: chiara.arrighi@unifi.it DOI 10.3311/FLOODRisk2020.9.15
} 
11. Fuchs, S. Heiser, M., Schlögl, M., Zischg, A., Papathoma-Köhle, M. and Keiler, M. (2019): Short communication: A model to predict flood loss in mountain areas. In Environmental Modelling \& Software 117, pp. 176-180.

12. Gerl, T., Kreibich, H., Franco, G., Marechal, D. and Schroter, K. (2016): A Review of Flood Loss Models as Basis for Harmonization and Benchmarking. In PloS one 11 (7), pp. e0159791

13. Jongman B., Kreibich H. , Apel H., Barredo J. I., Bates P. D., Feyen L., Gericke A., Neal J., Aerts J. C. J. H. and Ward P. J., (2012) Comparative flood damage model assessment: towards a European approach, Nat. Hazards Earth Syst. Sci., 12, 3733-3752

14. Jonkman, S. N., Bočkarjova, M., Kok, M. and Bernardini, P. (2008): Integrated hydrodynamic and economic modelling of flood damage in the Netherlands. In Ecological Economics 66 (1), pp. 7790. DOI: $10.1016 /$ j.ecolecon.2007.12.022

15. Liaw, A. and Wiener, M. (2002) Classification and Regression by random Forest, R News, 2, 18-22, http://CRAN.R-project.org/doc/Rnews/, 2002

16. Merz, B., H. Kreibich and U. Lall (2013) Multivariate flood damage assessment: a tree-based datamining approach, Nat. Hazards Earth Syst. Sci., 13, 53-64

17. Molinari D., Scorzini A.R. (2017) On the influence of input data quality to flood damage estimation: The Performance of the INSYDE Model, Water, 9(9), 688

18. Molinari, D., de Bruijn, K. M., Castillo-Rodríguez, Jesica T., Aronica, G. T. and Bouwer, L. M. (2019): Validation of flood risk models: Current practice and possible improvements. In International Journal of Disaster Risk Reduction 33, pp. 441-448

19. Molinari, D., Scorzini, A.R., Arrighi, C., Carisi, F., Castelli, F., Domeneghetti, A., Gallazzi, A., Galliani, M., Grelot, F., Kellermann, P., Kreibich, H., Mohor, G.S., Mosimann, M., Natho, S., Richert, C., Schroeter, K., Thieken, A., Zischg, A.P. and F. Ballio (2020) Are flood damage models converging to reality? Lessons learnt from a blind test, Nat. Haz. and Earth Syst. Sci. Discuss., https://doi.org/10.5194/nhess-2020-40, in review

20. Richert, C., \& Grelot, F. (2018). Comparaison des modèles de dommages nationaux avec les données de sinistralité.

21. Rouchon, D., Christin, N., Peinturier, C. and Nicklaus, D. (2018): Analyse multicritères des projets de prévention des inondations. Guide méthodologique 2018. Théma - Balises. Ministère de la Transition Écologique et Solidaire, Commissariat général au développement durable.

22. Schröter, K., Kreibich, H., Vogel, K., Riggelsen, C., Scherbaum, F. and Merz, B. (2014). How useful are complex flood damage models? Water Resources Research, 50(4), 3378-3395.

23. Scorzini A.R., Radice A. and Molinari D., (2018) A New Tool to Estimate Inundation Depths by Spatial Interpolation (RAPIDE) Design, Application and act on Quantitative Assessment of Flood Damage, Water, 10, 1805
24. Teng, J., Jakeman, A.J., Vaze, J., Croke, B.F.W., Dutta, D. and Kim, S., 2017. Flood inundation modelling. A review of methods, recent advances and uncertainty analysis. Environmental Modelling \& Software 90, 201-216.

25. Thieken, A., Olschewski, A., Kreibich, H., Kobsch, S. and Merz, B. (2008): Development and evaluation of FLEMOps - a new Flood Loss Estimation MOdel for the private sector. - In: Proverbs, D., Brebbia, C. A., Penning-Rowsell, E. (Eds.), Flood Recovery, Innovation and Response I, WIT Press, pp. 315-324.

26. Wagenaar, D., Lüdtke, S., Schröter, K., Bouwer, L. M. and Kreibich, H. (2018): Regional and Temporal Transferability of Multivariable Flood Damage Models. In Water Resour. Res. 54 (5), pp. 3688-3703.

27. Zischg, A.P., Mosimann, M., Bernet, D.B. and Röthlisberger, V. (2018): Validation of 2D flood models with insurance claims. In Journal of Hydrology 557, pp. 350-361. 